\title{
REGIMES DE BEM-ESTAR E POBREZA NA AMÉRICA LATINA
}

\author{
INTRODUÇÃO
}

Anete Brito Leal Ivo*

Constitui um fato reiterado a consideração de uma "crise" do Estado de Bem-estar social e a imperiosa necessidade de se pensar em alternativas que visem à otimização dos princípios de justiça e bem-estar social. Essas alternativas são necessariamente interdisciplinares e envolvem as intrínsecas relações da dinâmica dos mercados de trabalho, e seus aspectos institucionais, como os princípios e valores que ordenam e qualificam os projetos em debate. É possível encontrar as origens do modelo de Bem-estar social desde o final do século XIX, mas aquele a que nos referimos hoje associa-se às reformas ocorridas na Europa do pósguerra, que visavam a coletivizar os riscos através de mecanismos redistributivos e com base na solidariedade nacional.

A crítica ao modelo não é nova e acompanha toda sua existência, já que estabelece uma linha divisória entre projetos e forças políticas e sociais diversas, que postulam por maior ou me-

\footnotetext{
* Pesquisadora do Centro de Recursos Humanos da Universidade Federal da Bahia. R. Caetano Moura, 99, $1^{\circ}$ sub-solo (Federação). Cep 40.210-320. Salvador - Bahia. Brasil. anetivo@ufba.br.

Agradeço a Celina Souza e Elsa Kraychete pelos comen-
} tários a este texto. nor liberalização de mercados, maior ou menor grau de desmercantilização ${ }^{1}$ da força de trabalho em relação ao capital, questões necessariamente tensas, fontes de conflitos e críticas permanentes entre interesses de classes divergentes. Segundo Perrin (1969), na década de 50, os críticos a esse modelo entendiam que essas políticas constituíam uma ameaça ao crescimento econômico estável e uma fonte de pressão inflacionária de difícil controle pelo Estado. A evolução do capitalismo em ritmos de crescimento acelerado tornou essas críticas insustentáveis. Na década de 60, as críticas originaram-se da esquerda, insatisfeita em matéria de "igualdade", o que acabou resultando em aumento de benefícios, ampliação de cobertura e maior acessibilidade generalizada a esses direitos (Apud Esping-Andersen, 2001, p. 87). ${ }^{2}$ Na década de 70,

${ }^{1}$ Corresponde à expressão "decommodification", usada por Gosta Esping-Ansersen (1990). Tenho usado a expressão como "desmercantilização da força de trabalho" (Ver Ivo, 2004, 2005), que significa o acesso dos trabalhadores a uma série de seguros e prestações sociais, baseados em direitos e políticas sociais, que expressam um processo parcial de socialização da economia.

${ }^{2}$ Essa tendência teve efeitos sobre países em desenvolvimento e se expressou em intensas mobilizações sociais na década de 70 e 80 . Os resultados desses movimentos se traduziram na expansão de direitos sociais básicos de 
o diagnóstico da governabilidade para a América Latina (Ivo, 2001), ${ }^{3}$ que resultou em recomendações para reformas eajustes do Estado, aponta como fatores determinantes: a crise fiscal, provocada por demandas sociais crescentes; o excesso de democracia, que provocou uma crise de autoridade; e o provincianismo dos Estados nacionais (Cf. Ivo, 2001, p. 48-49). Mais tarde, em 1981, a conferência internacional da OCDE ressaltou, de novo, as conseqüências negativas das políticas de bem-estar para o crescimento econômico, entendendo que o estancamento econômico, a inflação e o crescente desemprego eram efeitos secundários, diretamente ligados aos excessivos encargos dos estados nacionais. Vinte anos após o levantamento dessas questões, estamos de novo diante da formulação de novas críticas. Inúmeros fatores são levantados como determinantes nesta nova fase, impondo que a sociedade se abra à crítica e à busca de alternativas de bem-estar social, dentro dos objetivos primeiros de justiça social: de um lado, os novos paradigmas tecnológicos de produção e reorganização do trabalho tiveram implicações sobre a flexibilização das relações de trabalho, o desemprego massivo de setores assalariados, a precarização da força de trabalho e o empobrecimento de setores médios urbanos. Por outro, as novas formas de integração econômica e política da globalização envolveram mudanças institucionais, no papel do Estado em matéria social e a redefinição de responsabilidades e competências entre o setor público e o setor privado, etc., com repercussões diferenciadas sobre países e regiões.

Em suma, o debate sobre regimes de bemestar social ${ }^{4}$ não só está no centro das mudanças cidadania inscritos na Constituição Brasileira de 1988 como a Previdência especial rural e o Benefício da Prestação Continuada, além de benefícios dirigidos aos direitos de minorias.

${ }^{3}$ Sobre o detalhamento do diagnóstico da governabilidade, ver Ivo (2001, p.48-49), onde são resumidas as principais linhas do documento A crise da democracia de Samuel Huntington; Crozier e Watanuzki, 1975, no qual os autores argumentam a incontrolabilidade da crise fiscal nos centros do capitalismo avançado e sugerem medidas restritivas à operacionalização da democracia.

${ }^{4}$ Entende-se por regimes de bem-estar a combinação de pautas, explícitas ou não, que determinam a forma de acesso às principais instituições de política social (Lo Vuolo, 2004, p.20). A análise detalhada desses regimes para a região é feita por Barba, neste dossiê. em curso, expressando inflexões dos novos modos de reprodução da acumulação globalizada do capital, como impõe que se discutam alternativas no âmbito dos modelos de organização social e do padrão do bem-estar social que se quer alcançar.

O esforço da busca de alternativas não é tarefa simples, primeiramente pelas dificuldades de compartilhar questões ainda pouco conhecidas ou parcialmente desconhecidas da maioria; em segundo lugar, porque estamos falando de uma realidade submetida a mudanças radicais, mas que ainda não conta com paradigmas que sustentem quadros referenciais consistentes, ou algumas dessas categorias ainda não foram suficientemente submetidas à crítica; em terceiro lugar, porque, no campo dessas mudanças, patinamos sobre novos princípios e novas categorias de análise que, muitas vezes, aproximam tradições de pensamento opostas, como liberalismo e socialismo, como indica Lo Vuolo, 2004 a respeito da renda mínima de cidadania. Essa zona cinzenta ${ }^{5}$ gera polissemia conceitual e pouca clareza quanto à direção da ação pública.

Entendo que esse quadro nebuloso participa, em realidade, de movimentos de construção de hegemonia e contra-hegemonia no processo de transição em curso $^{6}$, no qual são os princípios que organizaram a formação do Estado de Bem-estar social e a construção dos paradigmas sobre os quais ele se assentou que estão em questão.

As mudanças promovidas pelas instituições internacionais, como o Banco Mundial, seja quanto à ênfase no combate à pobreza, seja pelos arranjos institucionais que acompanham as novas recomendações, têm sido objeto de acompanhamento e críticas da academia, por analistas acadêmicos e pelas redes de políticas sociais globais. ${ }^{7}$ No entanto, é relativamente grande a ênfase, entre estudio-

\footnotetext{
${ }^{5}$ Refiro-me ao caráter nebuloso e ainda pouco claro, porque subordinado a contextos conceituais e valorativos distintos.

${ }^{6}$ Ver, a respeito, Ivo (2006).

${ }^{7}$ Importante reconhecer que alguns dos processos implantados no Brasil resultaram internamente de demandas democráticas, que envolviam garantias constitucionais de repasses de recursos na implementação e universalização de políticas sociais para esferas locais, no caso da descentralização, como os Fundos Constitucionais de saúde, educação e assistência.
} 
sos, no fato de que as pressões da globalização são mediadas pelas capacidades institucionais, e essa avaliação tem estimulado estudos de caráter institucional que analisam arranjos de políticas nacionais e coalizões de interesses. No entanto, cada vez mais se reconhecem, também, os limites de uma percepção exclusivamente instrumental dessas análises, ${ }^{8}$ impondo que se avance sobre as implicações políticas que envolvem o encaminhamento dos velhos dilemas que conformaram a formulação da questão social, ${ }^{9}$ no campo das tensões entre forças sociais no contexto da modernidade. $\mathrm{E}$ essa dimensão é, necessariamente, interdisciplinar. Essas mudanças constituem-se, ao mesmo tempo, em desafios no campo da pesquisa, quanto instigam o aprofundamento de dimensões qualificadoras do tipo de sociedade e dos níveis de bem-estar que estão sendo almejados.

Portanto, o debate é antigo e tem se enriquecido atualmente, mas nem sempre ganha clareza. Ele envolve: discussões relativas à configuração da ordem social e à construção de novos paradigmas de compreensão da modernidade na sua fase madura, de tradições disciplinares e políticas diversas (Ulrich Beck; Anthony Giddens; Alain Tourraine; Bruno Latour); a discussão sobre os dilemas da sociedade do trabalho e os regimes de proteção social, frente aos novos paradigmas tecnológicos e às mudanças demográficas (André Gorz; Claus Offe; Pierre Rosanvallon; Robert Castel, e o próprio Beck, Gosta Esping Andersen, entre outros); ou aqueles de natureza sociológica, que abordam questões relativas a processos civilizatórios, a partir do entendimento dos pilares da "questão social" na modernidade (Castel, 1995; Rosanvallon, e Fitoussi, 1996, entre outros) e que dizem respeito à natureza do contrato social,

\footnotetext{
${ }^{8}$ O próprio Esping-Andersen, em seu artigo "Burocratas o Arquitetos?" (2001, p. 93-94), indica a necessidade de privilegiarem-se visões de conjunto, que envolvam aspectos sociais, demográficos e do mercado de trabalho.

${ }^{9}$ Formulada em termos de busca de mediações capazes de encaminhar o dilema republicano, assentado nos valores de igualdade e liberdade para todos, no contexto socioeconômico profundamente desigual do capitalismo. O livro de Karl Polanyi [1944] A Grande Transformação (2000) apresenta magistralmente o conjunto de leis e dispositivos criados na Inglaterra para encaminhar essas questões.
}

a contradições e forças políticas e sociais, em suma, à questão dos vínculos sociais.

A diversidade de formação da cultura política nos países latino-americanos e as diferentes experiências de configuração dos mercados de trabalho impõem que se considere diferentemente o impacto dessas reformas sobre a região. Na Europa, a questão central é saber "como garantir qualidade de bem-estar social frente às mudanças no mundo do trabalho e no perfil demográfico da população". No âmbito desse debate, vem sendo discutida, desde meados da década de 80 , a Renda Mínima de Inserção ou Renda Cidadã e as formas de seguridades mínimas do cidadão, desvinculadas da condição do trabalho assalariado permanente. Ou seja, alternativas que buscam vincular a proteção e as seguridades básicas à condição da cidadania e não apenas ao trabalhador assalariado. ${ }^{10}$ Em torno de encaminhamentos de mais longo prazo, há também um grande consenso, na Europa, sobre o papel da educação, no sentido de maximizar as capacidades produtivas humanas, como recurso fundamental não só para enfrentar o futuro incerto, mas como capacidade central ao exercício da democracia. Esse é um campo de grandes polêmicas, especialmente nos países da América Latina, quando confrontamos os objetivos da "capacitação" à institucionalidade e qualidade educacionais realmente existentes e o perfil do mercado de trabalho. A distribuição da ocupação por escolaridade ${ }^{11}$ mostra uma seletividade crescente do mercado de trabalho, vez que a escolaridade mínima representa um requisito progressivamente relevante no recrutamento de pessoas para o mercado de trabalho. Se esse dado ${ }^{10}$ A esse respeito, ver alguns trabalhos como Van Parijs, 1995 ; Suplicy, 1991, 2002, entre outros.

${ }^{11}$ Dados do PNAD/IBGE, 1992, 1998, 2004 (Microdados) apresentados em Dedecca; Rosandinski; Barbieri; Jungbluth (2006), revelam uma redução dos ocupados com até o $1^{\circ}$ grau incompleto de escolarização, enquanto aumenta a ocupação daqueles com $2^{\circ}$ grau completo, no período. Ou seja, se o mercado exige postos de maior qualificação, por outro lado, o sistema educacional no Brasil apresenta níveis de desempenho bastante distantes de outros países. Por exemplo, o Brasil e a Coréia do Sul gastavam, em final de 90 e 2000, respectivamente, 4,3 e 4,2\% do seu PIB em educação; no entanto, o gasto per capita sul coreano representava mais que o triplo do brasileiro. Ademais, o gasto com educação, em termos 
atesta a importância da escolaridade quanto aos objetivos futuros das políticas, revela também que, no estágio em que nos encontramos, essa variável ainda se constitui em mais um obstáculo à inserção social qualificada no mercado de trabalho.

Na América Latina, a vigência das reformas da década de 90 obedeceu a princípios e valores diferentes daqueles que orientam o debate na Europa, e a situação prevalecente de informalidade e pobreza da força de trabalho agrava ainda mais nossas fragilidades, “diante das perversas formas globalizadas da competição internacional, que pressionam pela ‘redução do custo trabalho' e [...] por modelos redutores de reforma da previdência como meio de redução do deficit fiscal.” (Draibe, 2003). Essas dimensões desfavoráveis tornam particularmente complexas as alterações que ocorrem no âmbito do mercado de trabalho e as alternativas orientadas para um modelo residual. ${ }^{12}$ EspingAndersen (2003), examinando o processo de reformas em países latino-americanos a partir da ótica européia - tanto pelo elo comum quanto pelas variações - considera essas questões extremamente complicadas. Para ele, "embora os problemas sejam os mesmos, as razões são bastante diferentes" (grifo meu). Observando comparativamente essas experiências, o autor considera que: (i) na Europa, o objetivo da eficiência econômica dos planos previdenciários está subordinado ao princípio de justiça e bem-estar; na América Latina, as reformas parecem ter sido implantadas segundo critérios de eficiência, com pouca consideração com a maximização do bem-estar; (ii) na Europa, o centro da questão diz respeito aos padrões demográficos do perfil dos contribuintes, enquanto que, na América Latina, o problema diz respeito ao perfil do mercado de trabalho, com poucos contribuintes; (iii) na Europa, um dos problemas do desgaste dos sistemas de repartição de renda é o crescimento sustentado do salário real por longo prazo, enquanto que, na América Latina, o empre-

per capita, nos países desenvolvidos (média de US\$ 1.300, em 2001), era cerca dez vezes superior à de países como o Brasil (Cf. Gimenez; Fagnani, 2006).

${ }^{12}$ Ver, a respeito, artigo de Fleury (1998) e o artigo de Carlos Barba, neste dossiê. go informal prevalece, e a distribuição de renda é extremamente desigual (grifos meus), com tendência, acrescento, de rebaixamento do valor do salário real. ${ }^{13}$

As mudanças mais recentes de reestruturação da economia, nos países da América latina, ocorrem num contexto em que a cidadania não significou a completa integração da massa de trabalhadores ao regime salarial estável, em que a pobreza constitui um fenômeno estrutural de massa e não uma questão residual e (ou) emergente, e em que esse estado de pobreza também está associado a dificuldades de acesso a inúmeros serviços urbanos e sociais.

Como analisei em outros trabalhos (Ivo, 2001), com base na matriz da relação salarial estável e de compromissos corporativos entre os trabalhadores e o Estado, essa relação potencializou gradativamente os direitos sociais de proteção, estendendo-os ao conjunto da população, beneficiando, inicialmente, o núcleo familiar dos trabalhadores assalariados e estendendo-se, a partir daí, e com base na força de pressão do movimento dos trabalhadores, ao conjunto da sociedade. Portanto, mesmo apresentando uma matriz salarial incompleta, a condição de proteção do núcleo assalariado e protegido do mercado de trabalho permitiu a formação de uma rede de sociabilidade e de cobertura ou proteção que ultrapassava o mundo do trabalho e a proteção individual, expandindo a proteção ao núcleo da família e potencializando as condições de sociabilidade e integração social das famílias de trabalhadores rurais e urbanos. A universalização dos direitos sociais e o acesso às políticas de proteção resultaram, pois, de um tipo de compromisso corporativo do Estado com o núcleo central dos trabalhadores assalariados, pelo

${ }^{13}$ Dados da PNAD (2005, p.79) mostram redução dos índices de desigualdade social da renda trabalho, no Brasil, com o Índice de Gini, que passou de 0,585, em 1995, para 0,544, em 2005. Eles revelam desconcentração da renda, favorável aos que se situam até dois salários mínimos, como resultado dos ganhos reais do salário mínimo, das transferências massivas do Programa Bolsa Família e da redução do preço dos artigos que compõem a cesta básica. No entanto, os estratos de renda acima de dois salários mínimos apresentam queda de rendimento, no período, com uma ligeira recuperação entre 2004 e 2005 (Cf. Ivo, 2006). 
poder de força e barganha desses trabalhadores, cujos efeitos sociais repercutiram sobre as condições de reprodução das famílias trabalhadoras, em geral (Ivo, 2001, p. 120).

No contexto presente, a precarização das relações de trabalho afeta diretamente o setor formal do mercado de trabalho, antes propulsor de uma dinâmica integrativa de proteção social ampliada. Por outro lado, a magnitude do fenômeno da pobreza na região ${ }^{14} \mathrm{e}$ as taxas elevadas das desigualdades sociais apontam para limites de muito dos programas de transferência de renda, cujos valores não chegam a retirar os indivíduos da linha da pobreza, e se situam abaixo de um patamar de bem-estar social capaz de ultrapassar o simples estágio de necessidades mínimas, em termos de acesso a capacidades propulsoras à condição de liberdade, para falar com base nos paradigmas liberais de Amartya Sen. Ao contrário, a competitividade globalizada pressiona para a 'redução do custo trabalho' e para a adoção de modelos de proteção nos limites dos mínimos sociais, como afirma Draibe (2003), agudizando um conflito redistributivo na base da pirâmide (Theodoro e Delgado, 2003) entre "pobres" e "quase pobres" (Ivo, 2004).

Nesse sentido, e tendo em vista a especificidade do processo do desenvolvimento das sociedades latino-americanas, não se pode compreender as mudanças contemporâneas ignorando a evolução e o próprio princípio do valor do trabalho - dos seus modos de institucionalização e das múltiplas funções de integração social em cada sociedade. Assim, relacionar a dinâmica do trabalho à da pobreza constitui uma dimensão fundamental e crítica das mudanças contemporâneas, especialmente na América latina. ${ }^{15}$ Efetivamente, no curso da recente transição, o tratamento da questão social vem enfatizado a luta contra a pobreza como

${ }^{14}$ Esse fator tem, na região, um peso considerável e, segundo dados do Panorama social de América Latina de 2005, da Comissão Econômica para América Latina y el Caribe (CEPAL, 2006), 39,8\% da população da região vive em condições de pobreza (ou seja, 209 milhões de pessoas), enquanto $15,4 \%$ da população (81 milhões de pessoas ) ainda vive em condição de pobreza extrema ou de indigência.

${ }^{15}$ Ver, a esse respeito, o artigo de Elsa Kraychete e Ângela Borges (2007), neste dossiê. compromisso ético e prioridade da agenda da ação social pública de todos os países, dissociado da dinâmica do mercado de trabalho. Esse processo conduz a uma separação entre trabalho e proteção, proteção e solidariedade nacional, que caracterizava o desenho do modelo de bem-estar do pós-guerra (Ivo, 2005, 2006). Seus resultados reais têm se expressado em perda de qualidade do trabalho, na formação de "novos pobres"16 e empobrecimento de setores das classes médias, na radicalização da individualização e segmentação da assistência, acabando por formar também um contingente de indivíduos que estão fora dos sistemas securitários garantidos constitucionalmente pelo Estado efora dos benefícios dos programas focalizados, os "no man land" apontados por Lautier (1999, apud Ivo, 2001). Um trabalho paradigmático sobre a pobreza e o desenvolvimento, nos anos 90, para além de uma dimensão exclusivamente economicista, foi o de Amartya Sen, Prêmio Nobel de economia em 1998. Na crítica à abordagem da pobreza por insuficiência de renda, ele formulou uma concepção de pobreza, na década de 80 , como privação de capacidades. Essa abordagem orientou os relatórios do Programa das Nações Unidas para o Desenvolvimento, PNUD (1997), quanto ao desenvolvimento social e humano e as metodologias de mensuração da pobreza segundo necessidades básicas, induzindo a necessidade de democratização do acesso a capacidades (educação, saúde, poder, etc.) que permitam aos pobres transformarem-se em sujeitos de sua luta. Sem menosprezar fatores econômicos, suas reflexões remetem a questão da pobreza ao campo da liberdade e da emancipação social. Para ele, não basta ter recursos econômicos, se não se consideram as possibilidades de

${ }^{16}$ A noção de novos pobres, originalmente mais adotada nos Estados Unidos, abarca aqueles que não conseguem reciclar-se no âmbito do trabalho e que não atendem às pautas culturais da modernidade, e os que se distanciam das exigências de uma sociedade liberal, que garante igualdade de oportunidades, mas pune duramente as más decisões dos projetos individuais. Atualmente, essa noção tem sido usada para expressar os processos de fragmentação e precarização social, num contexto de alta competitividade e com o empobrecimento de grandes setores da classe média. (Cf. Ivo e Warren-Sherer, 2004). 
convertê-los em capacidades de ação (Sen, 2000). ${ }^{17}$

No encaminhamento da questão da pobreza, o Banco Mundial (2001) ${ }^{18}$ entende que mobilizar o potencial dos pobres, da perspectiva liberal, implica aproveitar a capacidade existente nas comunidades, canalizando-a para resolver, a um só tempo, os problemas materiais da pobreza, da participação e da integração social, através de sua inserção no mercado. Implica reconverter os "ativos" dos pobres (em termos de bens de base disponíveis), para resolver a sua própria condição de vulnerabilidade social, integrando-os ao mercado e ultrapassando a condição de pobreza.

Essa matriz paradigmática sobre vulnerabilidade social, formulada pelo Banco Mundial, estimula um conjunto de pesquisas que buscam aferir tanto as condições de acessibilidade da população pobre aos serviços públicos e sociais, como identificar, a partir da vivência das populações trabalhadoras em condições de pobreza, a formação de redes sociais de proteção no âmbito da sociabilidade primária desses indivíduos. Por outro lado, essa perspectiva alimenta também imensas polêmicas acadêmicas, segundo as quais essa percepção pode converter as mazelas sociais (dos parcos recursos das classes populares) em virtudes dos “ativos”; outros, contrariamente, destacam o caráter positivo desses ativos como produtos de formas de resistência e lutas das camadas populares.

Este dossiê oferece oportunidade para o diálogo, de uma perspectiva regional (América Latina), trazendo algumas dessas questões a partir e de três temáticas básicas:

(i) a primeira busca resgatar a heterogeneidade dos regimes de bem-estar social a partir de três núcleos de países da América latina;

${ }^{17}$ Inspirada nessa perspectiva, o PNUD, na década de 90 definiu desenvolvimento humano como o processo de alargamento das escolhas pessoais em termos de acesso a uma vida longa e saudável, aquisição de conhecimentos e acesso aos recursos necessários a um padrão de vida adequado. Agregou a essas escolhas outras dimensões políticas, como liberdade política, garantia de direitos humanos e oportunidades de os indivíduos e cidadãos serem criativos.

18 Apresento essa abordagem em Ivo (2001, 2003) e em outros trabalhos. Ver também os estudos de Duhau e Scheingard, 1997; Salazar, 1998; Osmond, 1998; Codes 2003 e Kraychette, 2005. (ii) a segunda procura apresentar algumas mudanças na matriz da estratificação social e nas relações complexas que ocorrem em alguns países; (iii) a terceira apresenta, a partir de diferentes metodologias, as condições de acessibilidade a políticas sociais, considerando a variável territorial da segregação como dimensão central da pobreza urbana.

O conjunto de artigos aqui apresentados indaga, portanto, sobre várias questões: quais os dilemas e limites que enfrentam os países latinoamericanos em relação aos regimes de bem-estar social implantados (mesmo que incompletos)? Quais as tendências resultantes na estratificação social a partir das reformas econômicas da década de 90, considerando-se, particularmente, a realidade de Cuba e do Brasil? Quais os dilemas postos entre a questão do bem-estar, o trabalho e a pobreza? Quais os efeitos da estratificação social sobre a estrutura urbana e as condições efetivas de acesso de grupos mais pobres às políticas públicas?

Com a preocupação de contribuir para esse debate, o conjunto dos artigos que integram o presente dossiê apresentam, portanto, de perspectivas distintas e com base em realidades diversas, as implicações dos processos de reforma em curso, a partir de diferentes escalas espaciais, de forma a resgatar a dimensão da heterogeneidade dos regimes de bemestar social na região. Carlos Barba, no artigo América Latina: Regímenes de bienestar en transición durante los años noventa, analisa as distintas trajetórias dos processos de ajuste econômico e reforma social sobre três conjuntos de países da região, questionando a tese que entende como única via possível a perspectiva residual dos regimes de bem-estar latinoamericanos. Para ele, é indispensável incorporar, na agenda pública, o tema da geração de empregos formais, acompanhados de direitos sociais mínimos, como elemento estratégico em termos sociais, para o que são imprescindíveis um papel ativo do Estado, que favoreça inversões produtivas geradoras de empregos de qualidade, e a recuperação de uma dimensão do mercado de trabalho como espaço modular da inclusão social.

Cuba representa uma experiência singular 
na América Latina em matéria de proteção social, caracterizada pelo acesso livre e universal à saúde, à educação e à proteção social, com grande impulso no país em capital humano, tema prioritário nas alternativas de desenvolvimento propostas tanto na Europa como nos divesos países da região. Mayra Espina, no artigo Recuperando la "cuestión social". El contexto teórico metodológico del debate y la experiencia cubana, mostra como "a transição socialista cubana se caracteriza por uma política social de integração, de caráter muito radical, centrada na igualdade, porque atua combinando instrumentos de intervenção simultânea sobre as relações de propriedade sobre os meios de produção e distribuição". Frente à crise dos anos oitenta, desencadeada pelo desaparecimento do campo socialista internacional, a autora revela como a reforma econômica cubana redefine uma estratificação social, orientada por novos níveis de desigualdades sociais, implicando um cenário qualitativamente distinto para a política social, especialmente porque os atores do desenvolvimento mudaram substancialmente suas possibilidades de ação, como agentes de mudança, e seus perfis subjetivos.

Elza Kraychette e Ângela Borges, no artigo Mercado de trabalho e pobreza: discurso e evidências na trajetória brasileira recente, discutem os pressupostos explicativos da origem da pobreza, considerando o contexto de virada dos anos 80 para os anos 90 do século XX e tomando como exemplo o caso brasileiro. Apresentam as abordagens que enfatizavam as causas estruturais da pobreza dominantes até a crise do fordismo - com ênfase na dinâmica do mercado de trabalho - e seu enfrentamento (as visões mais próximas do marxismo ou do modelo de desenvolvimento, no que toca às correntes estruturalistas). Seguem analisando a nova matriz discursiva sobre a pobreza e a sua gestão, que tem, na abordagem do Banco Mundial, a sua formulação mais paradigmática, apresentando, finalmente, considerações críticas sobre essa transição, com base em dados de funcionamento do mercado de trabalho nos anos típicos do desenvolvimentismo e no período mais recente (anos 90 e 2000).
Os dois últimos artigos deste dossiê trazem resultados originais de pesquisas realizadas em duas cidades brasileiras, São Paulo e Salvador, que ajudam a pensar problemas relativos à urbanização da pobreza no contexto contemporâneo, a partir de diferentes metodologias de avaliação, em que a variável territorial e espacial da segmentação urbana e seus efeitos sobre as condições de acessibilidade às políticas públicas é central.

Nessa linha, Haroldo Torres e Renata Bichir, no artigo Conseqüências da segregação residencial para as políticas públicas: o caso do atendimento básico em saúde em São Paulo, dialogam com algumas abordagens que procuram explicar as condições diferenciadas de acesso às políticas públicas e desenvolvem o argumento de que variáveis de diversas naturezas-demográficas, institucionais, espaciais, relativas ao associativismo, entre outras - devem ser consideradas, de modo a se construir um cenário mais completo das situações de acesso a políticas públicas. Oartigo apresenta resultados de um survey realizado pelo Centro de Estudos da Metrópole (CEMCEBRAP), em novembro de 2004, sobre as conseqüências da segregação residencial, ou seja, da concentração espacial de certos grupos sociais para as condições de acesso da população mais pobre do município de São Paulo ao atendimento básico de saúde. Os autores concluem reconhecendo os elevados níveis de coberturas do sistema básico de saúde pública, mesmo entre a população mais pobre do município de São Paulo, e, também, a institucionalização dos mecanismos de acesso.

Inaiá Carvalho e Gilberto Corso, no artigo Dinâmica metropolitana e segregação socioespacial, por fim, analisam a evolução recente dos padróes de segregação socioespacial e da conformação metropolitana de Salvador, primeira capital e atualmente a terceira maior cidade brasileira. Após uma revisão da discussão contemporânea sobre o papel das grandes metrópoles no contexto da globalização, os autores valem-se de dados originais sobre segmentação urbana e social do Observatório das Metrópoles para analisar a interatividade dessas variáveis sobre a estratificação social em Salvador. Concluem reconhecendo que o local de moradia e a 
precariedade e os altos custos dos transportes afetam as condições de vida e a rede de relações sociais de cada pessoa, a qualidade dos serviços públicos aos quais tem acesso, a sua probabilidade de conseguir trabalho e o tipo da sua ocupação.

Nos diversos estudos, permanece o desafio a um debate que fomente a inovação social.

\section{REFERÊNCIAS}

ANTUNES, Daví; GIMENEZ, Denis; FAGNANI, Eduardo. Crescimento econômico e pobreza. Carta Social e Trabalho, [S.l.], n. 4, maio/ago., p. 5-12, 2006.

CEPAL. Comissão Econômica para a América Latina e o Caribe. Panorama social de América Latina. Santiago de Chile: 2006

CODES, Ana Luíza. Combate à pobreza na América Latina: uma abordagem comparativa. In: SEI. Pobreza e desigualdades sociais. Salvador: 2003. p. 47-64. (Série Estudos e Pesquisas, 63), 2003.

DEDECCA, C.; ROSANDINSCKI, E.; BARBIERE, C. JUNGBLUTH, A. Salário Mínimo, benefício previdenciário e as famílias de baixa renda. In: ENCONTRO DA ABEP, 15, Caxambu, set., 2006.

DRAIBE, Sônia. Texto de apresentação do livro COELHO, Vera Schattan (Org.) A reforma da Previdência Social na América Latina. Rio de Janeiro: Editora da FGV, 2003.

DUHAU, E.; SCHEINGART, E M. Governabilidad y pobreza en el ámbito local: México, Colombia Centroamérica. In: RODRÍGUEZ, A; WINCHESTER, L. Ciudades y governabilidad en America Latina. Santiago de Chile: Ediciones SUR, 1997. p.61-97. (Colección estudios urbanos).

ESPING-ANDERSEN, G. The three worlds of welfare capitalism. Cambridge: Cambridge University Press, 1990.

$$
\text { Burocratas o arquitetos? In: }
$$

Presente $y$

\section{Aires: SIEMPRO/ Miño y Dávila, 2001. p. 85-120.}

. Uma perspectiva transatlântica da política de privatização latinoamericana. In: COELHO, Vera Schattan (Org.) A reforma da Previdência Social na América Latina. Rio de Janeiro: Editora da FGV, 2003. p. 13-26.

FLEURY, Sônia. Política social, exclusión y equidad en America Latina de los 90. Nueva Sociedad, Caracas, Editorial Texto/ FFE, n. 156, jul./ago., p 72-94. 1998.

IVO, Anete, Metamorfoses da questão democrática: governabilidade e pobreza. Buenos Aires: CLACSO, 2001.

Políticas Sociais de combate à pobreza nos anos 1990: novas teses, novos paradigmas. In: SEI. Pobreza e desigualdades. Salvador: 2003. p.7-28 (Série Estudos e Pesquisas, 63).

. A reconversão do social: dilemas da redistribuição no tratamento focalizado. São Paulo Perspectiva, SEADE, v. 18, n. 2, p. 57-67, abr./jun., 2004.

. The redefinition of the social issue and the rethoric on poverty during the 90. In: CIMADAMORE, Alberto; HARTLEY Dean; SIQUEIRA, Jorge (Eds.) The poverty of the State: reconsidering the role of the State in the struggle against global poverty. Buenos Aires: CLACSO/CROP, 2005. p. 65-90. (Publicado em português pelo CLACSO sob o título “A pobreza do Estado”, ago. 2006).
Inégalités, démocratie et pauvreté: les effets politiques des programmes ciblés au Brésil. In: Egalités et inégalités dans les Amériques. Paris: La Documentation Française, nov., 2006. No prelo

SHERER-WARREN, I. Pobreza, dádiva e cidadania. Introdução ao dossiê temático. Caderno $C R H$, v. 17, n. 40, p. 11-16, jan./abr., 2004.

KRAYCHETE, E. O Banco Mundial e o desenvolvimento das microfinanças em países da periferia capitalista. 2005. 222p. Tese (Administração) - Programa de Pós-graduação em Administração da UFBA. Salvador.

LAUTIER, Bruno Les politiques sociales en Amérique Latine. Propositions de méthode pour analyser un éclatement en cours. Cahiers des Amérique Latines, Paris, IHEAL Editions, n. 30, p. 19-44, 1999.

LO VUOLO, Ruben et al. Contra la exclusión. La proposta del ingreso ciudadano. Buenos Aires: CIEP; Miño y Dávila, 2004.

NAÇÕES UNIDAS. Relatório do Desenvolvimento Humano, 1997: desenvolvimento humano para erradicação da pobreza. New York: PNUD; Lisboa: Trinova Editora, 1997.

PERRIN, G. Refections on fifty years os social security. International Labor Review, [S.1.], n. 99, 1969.

PNAD/IBGE. Pesquisa Nacional de Amostra de Domcílios. Síntese de Indicadores, 2005.

POLANYI, K. [1944] A grande transformação. As origens da nossa época. Rio de Janeiro: Elsevier, 2000.

SEN, A. K. Desenvolvimento como liberdade. São Paulo: Cia. das Letras, 2000.

SUPLICY, Eduardo M. Programa e garantia de renda mínima. Brasília: Senado Federal, $1991 . \quad$. Renda de cidadania: a saída é pela porta. 2.ed rev. São Paulo: Cortez; Ed. Fundação Perseu Abramo, 2002.

THEODORO, M.; DELGADO, G. Política social: universalização ou focalização; subsídios para o debate. Boletim Políticas Sociais - Acompanhamento e análise. Brasília, DF: IPEA, n.7, 2003.

VAN PARIJS, Philippe. Mas allá de la solidarida. Los fundamentos éticos del Estado de Bienestar y de su supoeración. In : LO VUOLO, R et al (Org.) Contra la exclusión. La propuesta del ingresso ciudadano. Buenos Aires: CIEPP; Mino y Dávila, 1995.

WORLD BANK. WASHINGTON, D.C. World development report 2000/2001: attacking poverty. New York: Oxford University Press, 2001. 
Anete Brito Leal Ivo - Pesquisadora Sênior do CRH/UFBA e Professora da Pós-graduação em Ciências Sociais da Universidade Federal da Bahia. É pesquisadora associada do CREDAL/CNRS-Fr., desde 1996. Foi professora titular da Cátedra Simon Bolivar da Université de Paris III (2000) e professora convidada da Université de Paris XII (2006). É Mestre em Ciências Sociais pela UFBA e realizou estudos doutorais na Université de Paris III. Foi coordenadora de inúmeras cooperações acadêmicas com universidades francesas (1981-1996). Integra o G.P, Pobreza y políticas sociales - CLACSO. É editora do Caderno CRH desde 1996 e consultora de revistas científicas nacionais e internacionais e de agências de fomento, no Brasil e no exterior. Tem inúmeros artigos e livros, no Brasil e no exterior, destacando-se: Metamorfose da questão democrática: governabilidade e pobreza (Buenos Aires: CLACSO, 2001), ganhador do $2^{\circ}$ Concurso Internacional de Pesquisadores Seniores do CLACSO/ASDI. Seus trabalhos tratam sobre: modernidade e questão social; pobreza e desigualdades sociais; políticas sociais; Estado e movimentos sociais. 